\title{
Evaluación de recubrimientos biodegradables para la conservación en fresco de jitomate Kenton
}

\author{
Evaluation of biodegradable coatings for preservation of fresh Kenton tomato
}

\author{
Selene C. H. Rives-Castillo', Rosa I. Ventura-Aguilar², Mónica Hernández-López ${ }^{3}$, \\ Silvia Bautista-Baños ${ }^{3 *}$
}

\begin{abstract}
RESUMEN
El objetivo de este estudio fue evaluar recubrimientos comestibles biodegradables en la conservación poscosecha de jitomates variedad Kenton de dos estados de madurez (rayado y rojo claro) y almacenados a 10 y $25^{\circ} \mathrm{C}$. Se elaboraron recubrimientos de quitosano $1 \%$ adicionados con aceite esencial de orégano (AEO) a $0.005,0.01$ y $0.03 \%$ y cera de abeja $0.1 \%$. Se evalúo la producción de CO2, etileno, pérdida de peso, firmeza, SST, pH, acidez titulable, carotenoides y determinaciones microbiológicas y sensoriales. En general, el mayor efecto se observó en los jitomates color rojo claro y con el recubrimiento con la concentración de AEO de $0.03 \%$ i.e. mayor firmeza, menor pérdida de peso, aumento de carotenoides, menor incidencia y severidad de microorganismos (hongos, levaduras y bacterias) y fitopatógenos, y mayor calidad sensorial respecto al aroma, color y sabor. Los principales géneros de hongos que se aislaron fueron Alternaria, Cladosporium, Fusarium, Geotrichum y Botrytis.
\end{abstract}

PALABRAS CLAVE

Solanum lycopersicum L., quitosano, aceite esencial de orégano, cera de abeja, madurez

\section{ABSTRACT}

The objective of this study was to evaluate biodegradable edible coatings in the postharvest conservation of tomato variety Kenton of two stages of maturity, at different temperatures. Coatings with $1 \%$ chitosan added with oregano essential oil (EO) at $0.005,0.01$ and $0.03 \%$ and $0.1 \%$ beeswax were elaborated. The production of CO2, ethylene, weight loss, firmness, SST, pH, titratable acidity, carotenoids, and microbiological and sensory determinations were evaluated. In general, the highest effect was observed for the light red tomatoes, and for the coating with the EO concentration at $0.03 \%$ i.e. higher firmness, lower weight loss, increased of carotenoid. In general, the highest effect was observed for the tomatoes in the red-ripe maturity stage and for the coating with the highest concentration $(0.03 \%)$ of EO i.e. higher firmness, lower weight loss, increased of carotenoids, lower incidence and severity of microorganisms (fungi, yeast and bacteria) and phytopathogens, and higher sensory quality with respect to aroma, color and flavor. The main fungal genera that were isolated were Alternaria, Cladosporium, Fusarium, Geotrichum and Botrytis.

KEYWORDS

Solanum lycopersicum L., chitosan, oregano essential oil, beeswax, ripening

\footnotetext{
${ }^{1}$ Maestría en Ciencias Agropecuarias, Universidad Autónoma Metropolitana. Ciudad de México, México.

${ }^{2}$ Centro de Desarrollo de Productos Bióticos - CONACYT. Yautepec, Morelos, México.

${ }^{3}$ Instituto Politécnico Nacional, Centro de Desarrollo de Productos Bióticos. Yautepec, Morelos, México.

*Autor para correspondencia: Carretera Yautepec-Jojutla Km. 8. 62731 San Isidro, Yautepec, Morelos, México.

Correo electrónico: sbautis@ipn.mx
} 


\section{INTRODUCCIÓN}

En la actualidad las hortalizas son los cultivos con mayor demanda para su consumo en fresco (FAOSTAT 2015). A nivel mundial entre los productos hortícolas con mayor demanda se encuentra la familia de las solanáceas, la cual ocupa la mitad de la producción hortícola mundial. En particular, el jitomate (Solanum lycopersicum L.) es uno de los frutos con mayor demanda; sin embargo, si no se llevan a cabo buenas prácticas de conservación, durante la cosecha y almacenamiento, su vida de anaquel será corta e incrementará la presencia de microorganismos.

Con la finalidad de retardar el deterioro del producto, actualmente se han aplicado películas comestibles biodegradables a base de productos no tóxicos, como el quitosano adicionado con derivados de plantas como los aceites esenciales. Estos tratamientos poscosecha tienen la doble función de conservar y proporcionar propiedades antimicrobianas (Ramos-García et al. 2010).

El uso de recubrimientos a base de quitosano (polisacárido natural, no tóxico y biodegradable, que se obtiene del exoesqueleto de los crustáceos mediante la desacetilación parcial de la quitina) (Rodríguez-Pedroso et al. 2009) se ha experimentado en numerosos productos hortofrutícolas con una efectividad notable como cubierta polimérica que extiende la vida de anaquel $\mathrm{y}$, además, favorece el control de hongos y bacterias (Bautista-Baños et al. 2017).

Por otro lado, la aplicación de aceites esenciales como agentes antimicrobianos durante la postcosecha de productos hortofrutícolas (Sivakumar y Bautista-Baños 2014) se considera una alternativa acertada en el manejo de enfermedades que se presentan en esta etapa. En el caso del aceite esencial de orégano, Origanum vulgare L. (Lamiaceae), García-Camarillo et al. (2006) reportaron su efecto inhibitorio sobre Aspergillius flavus en nuez pecanera [Carya alba (L.) Nutt. ex Elliott, Juglandaceae] en una concentración de $2000 \mathrm{mg} \mathrm{L}^{-1}$. En otra investigación realizada por Pontigo-Suárez et al. (2015) se reportó también un efecto antifúngico y antibacteriano sobre Colletotrichum gloeosporioides y Salmonella sp., respectivamente, aislados de frutos de papaya a una concentración de $500 \mathrm{mg} \mathrm{L}^{-1}$.

En la elaboración de recubrimientos comestibles se han utilizado diferentes ceras entre las que destaca la cera de abeja, la cual mejora el aspecto de los productos hortofrutícolas (Ramos 2012). La cera de abeja está constituida principalmente por una mezcla de hidrocarbonos, ésteres, alcoholes y ácidos los cuales son compuestos que tienen efectos antimicrobianos (Tulloch 1969).

Al respecto, Fagundes et al. (2014) elaboraron un recubrimiento comestible con cera de abeja, hidroxipropil-metil-celulosa (HPMC) y diferentes sales para su aplicación en jitomate tipo Cherry previamente inoculado con moho gris (Botrytis cinerea Pers.: Fr). Los resultados demostraron que su aplicación no afectó el proceso de maduración durante el almacenamiento y además retrasó el desarrollo del moho gris. Por su parte, Villegas y Albarracin (2016) evaluaron la combinación HPMC y cera de abeja en moras de castilla (Rubus glaucus Benth), con la que se logró aumentar la vida útil de esta fruta hasta por 15 días a $4^{\circ} \mathrm{C}$.

No obstante, aún no se ha reportado el efecto del aceite esencial de orégano incorporado en recubrimientos comestibles a base de quitosano en los parámetros de calidad poscosecha del jitomate, durante un proceso de almacenamiento y comercialización, en el cual el producto se almacena a temperatura controlada y posteriormente se mantiene a temperatura ambiente.

En este sentido, esta investigación tuvo como objetivo evaluar la aplicación de recubrimientos biodegradables a base de quitosano adicionados con cera de abeja y diferentes concentraciones de aceite esencial de orégano, en relación con la vida de anaquel, calidad sensorial y efecto antimicrobiano en jitomates variedad Kenton color rayado y rojo almacenados a $10 \pm 2^{\circ} \mathrm{C}$ (12 días) y $25 \pm 2^{\circ} \mathrm{C}$ (6-8 días).

\section{MATERIALES Y MÉTODOS}

\section{Obtención del material vegetal y reactivos utilizados}

Los frutos de jitomate Kenton se cosecharon de invernaderos que se localizan en Yautepec, Morelos, México. Se evaluaron dos estados de madurez, acorde con la NMX-FF-031-1997-SCFI 6/20: rayado (entre 10\% y $30 \%$ de la superficie del tomate mostró un cambio definido del color verde hasta amarillo, rosado o rojo, o una mezcla de éstos) y rojo claro (entre 60\% y $90 \%$ de la superficie presentó color rosado/rojo o rojo). El aceite esencial de orégano se obtuvo de la compañía ORE (Chihuahua, México). Para la elaboración del recubrimiento se utilizó quitosano de peso molecular medio (grado de desacetilación=89\%) a 1\% (América Alimentos, Ingredientes Funcionales, Zapopan, Jalisco, México) y cera de abeja, grado alimenticio (Química Meyer, México). 


\section{Elaboración de los recubrimientos y manejo del experimento}

Los jitomates se seleccionaron por tamaño, color y apariencia. Estos se desinfectaron con una solución clorada al $1 \%$ y posteriormente se drenó el exceso de agua y se aplicaron los recubrimientos comestibles por inmersión.

Los recubrimientos se elaboraron de acuerdo con la metodología de Bautista-Baños et al. (2018) a partir de quitosano $1 \%$, ácido acético $1 \%$, cera de abeja $0.1 \%$, glicerol $0.3 \%$ y aceite esencial. Las concentraciones de aceite esencial fueron T1: $0.005 \%$, T2: $0.01 \%$, T3: $0.03 \%$ y T4: control sin recubrimiento. Finalmente, los jitomates se almacenaron por 16-18 días; 12 días a temperatura controlada de $102^{\circ} \mathrm{C}$ y 6-8 días adicionales de aclimatación a temperatura ambiente de $252^{\circ} \mathrm{C}$. Las evaluaciones se realizaron los días 0 , $3,6,9,12,14,16$ y 18 según la variable evaluada. Se utilizaron 10 frutos por tratamiento, cinco frutos de la temperatura controlada y cinco de la temperatura ambiente, para cada variable y día de evaluación.

\section{Variables fisiológicas: producción de $\mathrm{CO}_{2^{\prime}}$ etileno y pérdida de peso}

La producción de $\mathrm{CO}_{2}$ y etileno se cuantificó con la técnica de espacio-cabeza. En un recipiente hermético con volumen conocido se colocaron tres jitomates durante $1 \mathrm{~h}$, posteriormente, se tomó $1 \mathrm{~mL}$ del gas contenido en el espacio de cabeza, el cual se inyectó en un cromatógrafo de gases 7890B GC System (Agilent Technologies $^{\circledR}$, USA). El helio se utilizó como gas acarreador a una velocidad de flujo de $10 \mathrm{~mL} \mathrm{~min}^{-1}$. Se utilizaron los detectores (FID/TCD) y dos columnas. Las temperaturas del inyector y detectores fueron de 220,300 y $250^{\circ} \mathrm{C}$, respectivamente. La producción de $\mathrm{CO}_{2}$ y etileno se expresaron en $\mathrm{mL} \mathrm{kg}^{-1} \mathrm{~h}^{-1}$ y $\mu \mathrm{L} \mathrm{kg}$ $\mathrm{h}^{-1}$, respectivamente. Para la pérdida de peso se utilizó una balanza digital CS200 Compact Scale ${ }^{\circledR}$ (Ohaus, USA) se evaluó la diferencia entre el peso inicial y final y los valores se expresaron en porcentaje.

\section{Variables de calidad: color, firmeza, sólidos solubles totales, $\mathrm{pH}$, acidez titulable y carotenoides}

El color se midió con el colorímetro BC-10 (Kónica Minolta, Sensing, Américas, Inc., Japón), se tomaron los valores a y $\mathrm{b}$ en dos zonas opuestas del fruto y se calculó el ángulo matiz (h). La firmeza se evaluó en ambas caras con un penetrómetro 53205 Fruit Firmness Tester (Turoni $^{\circledR}$, Italia). Los valores se promediaron y se expresaron en Newtons (N). Los sólidos solubles totales (SST) se determinaron agregando directamente una gota de jugo del jitomate de ambas caras con ayuda de una pipeta, la cual se colocó sobre el sensor de un refractómetro de mano cat. 2111-N-1 (ATAGO ${ }^{\circledR}$, Japón) con escala de $0-32 \%{ }^{\circ}$ Brix. Se realizó una calibración con agua destilada antes de cada medición. Los resultados se reportaron como \% de SST. Para medir el pH se utilizó un potenciómetro (Navih ${ }^{\circledR} 51$ Horiba, Japón) con un intervalo de medición de $\mathrm{pH} 0$ a 14, y una exactitud de \pm 0.01 . La lectura se obtuvo colocando el electrodo en la solución de la muestra. Entre cada medición se lavó el electrodo con agua destilada.

El porcentaje de acidez titulable se obtuvo mediante una titulación con $\mathrm{NaOH}$ al $0.1 \mathrm{~N}$, usando como agente de contraste la fenolftaleína. El pH se ajustó a 8.1. Se consideró al ácido cítrico $(0.064 \mathrm{~g}$ meq $^{-1}$ ) por ser el ácido orgánico predominante en el jitomate. Para la extracción de carotenoides se utilizaron $2 \mathrm{~g}$ de cada fruto, el cual se maceró en un mortero con pistilo con $10 \mathrm{~mL}$ de hexano/acetona/ etanol (50:25:25 v/v). El homogeneizado se centrifugó en una centrifuga (Prism, Labnet ${ }^{\circledR}$, USA) a $6500 \mathrm{rpm}$ durante $30 \mathrm{~min}$ y el sobrenadante se aforó con $10 \mathrm{~mL}$ de hexano. Los carotenoides se determinaron por el método reportado por Rodríguez-Amaya (1999) con un espectrofotómetro Genesys 10s uv-vis ${ }^{\circledR}$ (Thermo, USA). Se midió la absorbancia de la solución a $450 \mathrm{~nm}$.

Se utilizaron 10 frutos por tratamiento, cinco frutos de la temperatura controlada y cinco de la temperatura ambiente, para cada variable y día de evaluación.

\section{Variables microbiológicas: pruebas microbiológicas, identificación e incidencia de hongos y severidad de la enfermedad}

Las pruebas microbiológicas se realizaron al término del experimento, 10 frutos por tratamiento, cinco frutos de la temperatura controlada y cinco de la temperatura ambiente, para cada variable, utilizando dos medios de cultivo: agar soya tripcaseína (AST) para determinar bacterias y papa dextrosa agar (PDA) (BIOXON, México) para determinar hongos y levaduras en general. Se elaboró una solución de agua peptonada ( $1 \mathrm{~g}$ de peptona de caseína $+8.5 \mathrm{~g}$ de cloruro de sodio +1 L de agua destilada), para lavar cinco frutos de jitomate por tratamiento bajo condiciones de esterilidad. Se tomó $1 \mathrm{~mL}$ del lavado y se realizaron diluciones $\left(10^{-6}\right)$, las cuales se vertieron en cajas Petri con AST o PDA, por triplicado y se incubaron durante $24 \mathrm{~h}$ a $30^{\circ} \mathrm{C}$. 


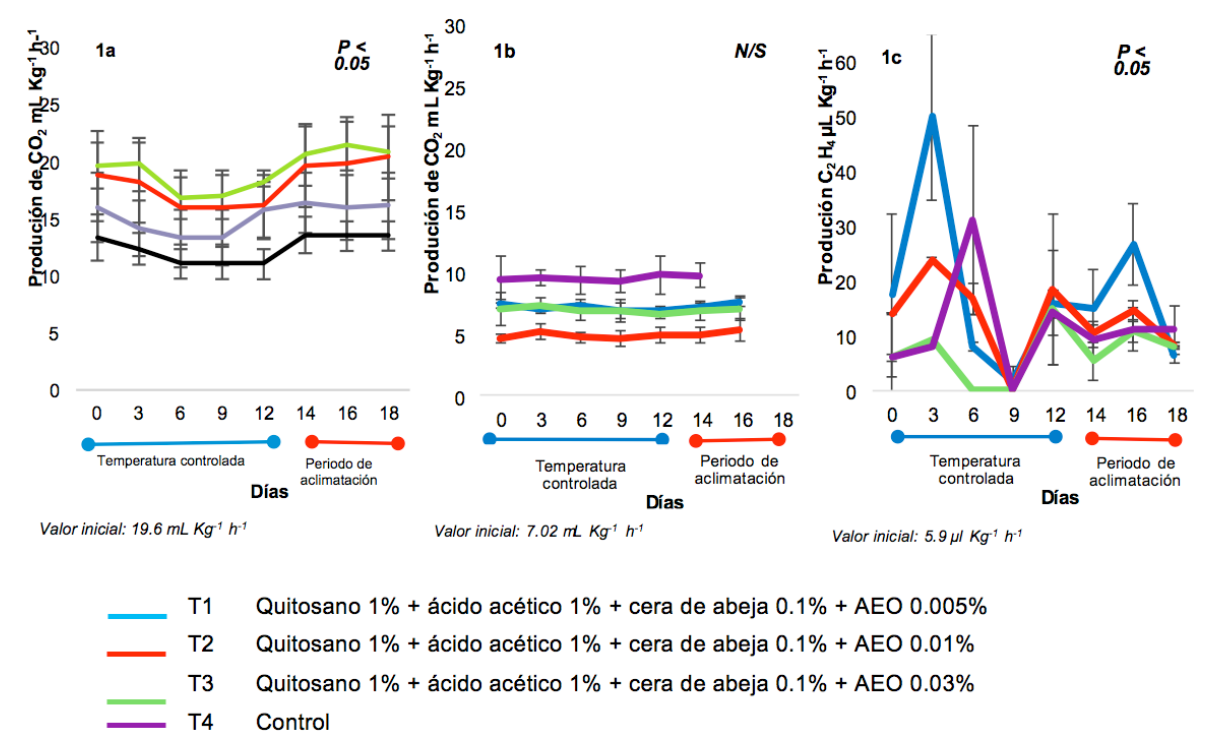

Figura 1. Producción de $\mathrm{CO}_{2}$ en frutos de jitomate color rayado (1a) y rojo claro (1b). Producción de etileno en frutos de jitomate color rayado (1c), tratados con cubiertas de quitosano adicionadas con cera de abeja y $\mathrm{AEO}$ y almacenados a $10^{\circ} \mathrm{C}$ y durante un periodo de aclimatación $\left(25 \pm 2^{\circ} \mathrm{C}\right)$.

También se aislaron e identificaron los hongos fitopatógenos a nivel de género de acuerdo a las claves taxonómicas especializadas de Barnett y Hunter (2003). La frecuencia de los hongos fitopatógenos se evaluó en base al número de jitomates infectados por cada género fúngico. La incidencia de la enfermedad se evaluó al término del almacenamiento de los frutos de jitomate y se determinó mediante el número de frutos infectados entre el número de frutos tratados por 100. El índice de severidad de los frutos se determinó con base en la escala propuesta por Ramos-García (2012) en donde: $1=0 \%, 2=1-25 \%, 3=26-50 \%, 4=51-75 \%$ y $5=76-100 \%$ de daño superficial.

\section{Evaluación sensorial}

Se llevó a cabo en el último día de almacenamiento del fruto, cuando se había alcanzado la madurez de consumo, por lo que las muestras no daban señas de daños físicos que limitaran su aceptación por los jueces evaluadores. Se utilizaron 10 frutos por tratamiento, incluyendo el tratamiento testigo, cinco frutos de la temperatura controlada y cinco de la temperatura ambiente. Estos se colocaron dentro de vasos de unicel blancos de $1 / 2$ litro. A cada vaso se le dio un número aleatorio de tres dígitos, el cual no se repitió entre sí y no fue consecutivo. Los frutos se aleatorizaron en cada uno de los vasos rotulados y se reservaron para la evaluación de los jueces. Para el sabor, los frutos se cortaron en cubos de aproximadamente $1 \mathrm{~cm}$ y se colocaron dentro de vasos rotulados con los números asignados en la aleatorización. Se entregaron dos muestras diferentes a evaluar a cada juez, en las cuales se calificó el aroma, color y sabor en una escala del 1 al 9. Donde: $1=$ Me disgusta extremadamente, $2=\mathrm{Me}$ disgusta mucho, $3=$ Me disgusta moderadamente, 4 $=$ Me disgusta poco, $5=\mathrm{Ni}$ me gusta ni me disgusta, $6=$ Me gusta poco, $7=$ Me gusta moderadamente, $8=$ Me gusta mucho, $9=$ Me gusta extremadamente. Para está evaluación se emplearon 40 jueces no entrenados.

\section{Análisis estadístico}

Se realizó un análisis de varianza con un arreglo de datos en diseño factorial, los datos se sometieron a una prueba de comparación de medias de Tukey $(p<0.05)$ y se presentan como la media \pm desviación estándar. Los datos se procesaron con el uso del software estadístico Sigmaplot v.13.

\section{RESULTADOS Y DISCUSIÓN}

\section{Respiración y etileno}

En la producción de $\mathrm{CO}_{2}$ se observaron diferencias significativas $(p<0.05)$ entre los tratamientos correspondientes al color rayado, no así en los de color rojo claro. En los jitomates color rayado se observó que, al transferirlos a la temperatura ambiente, su respiración se incrementó (figuras 1a, 1b). El máximo pico climatérico $\left(21.5 \mathrm{~mL} \mathrm{~kg}^{-1} \mathrm{~h}^{-1}\right)$ se obtuvo en los frutos en los que se aplicó quitosano $1 \%+$ 

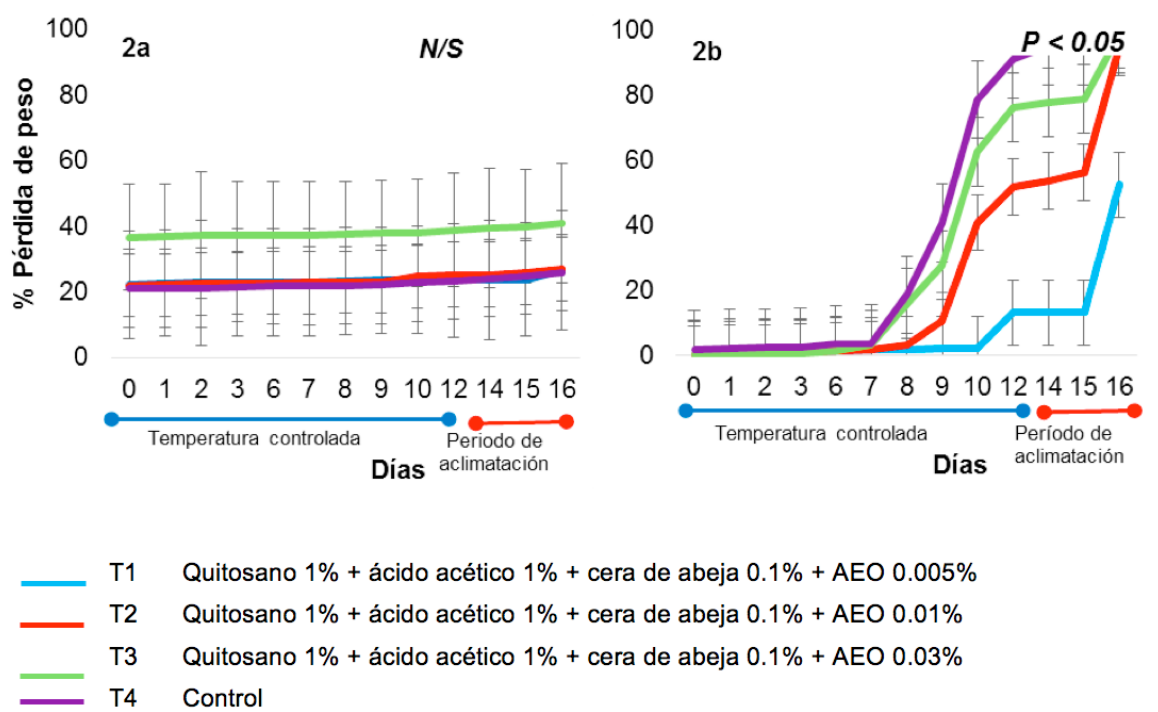

Figura 2. Porcentaje de pérdida de peso en frutos de jitomate color rayado (2a) y rojo claro (2b), tratados con cubiertas de quitosano adicionadas con cera de abeja y $\mathrm{AEO}$ y almacenados a $10^{\circ} \mathrm{C}$ y durante un periodo de aclimatación $\left(25 \pm 2^{\circ} \mathrm{C}\right)$.

ácido acético $1 \%$ + cera de abeja $0.1 \%+$ AEO $0.03 \%$. Al respecto, Bautista-Baños et al. (2018) reportaron que la tasa de respiración de jitomates tratados con cubiertas (quitosano + ácido oleico + aceite esencial de limón y quitosano + cera de abeja + aceite esencial de limón) dependió de la interacción de éstas con la temperatura de almacenamiento $\left(12 \mathrm{o} 25^{\circ} \mathrm{C}\right)$ y el estado de madurez (verde-maduro y rojo-maduro).

Con relación a la producción de etileno, la concentración fue muy baja en cada estado de madurez. El análisis estadístico mostró diferencias significativas $(p<0.05)$ sólo para el color rayado, en los cuales, se cuantificó un rango de producción de 0 a $50.8 \mu \mathrm{L} \mathrm{kg}^{-1}$ $\mathrm{h}^{-1}$ (figura 1c) mientras que en los frutos rojo claro, no se registró producción de etileno en ninguno de los tratamientos durante ambos periodos de almacenamiento.

Los resultados de la producción de etileno para los frutos tratados con las cubiertas coinciden con los que reportaron Dávila-Aviña et al. (2011) en el cv. 'Grandela' recubiertos con carnauba comercial (Strafresh $25015^{\mathrm{TM}}$ ) y aceite mineral (Stafresh $151^{\mathrm{TM}}$ ) ya que su aplicación disminuyó la producción de $\mathrm{CO}_{2}$ e inhibió la síntesis de etileno en los frutos que se cosecharon en estado verde-pintón y verde-rosa.

\section{Pérdida de peso}

Se observó que en los jitomates color rayado la pérdida de peso fue casi nula durante ambos periodos de almacenamiento (figura 2a) con un incremento muy ligero durante el periodo de aclimatación. Por el contrario, en los rojo claro, entre el día ocho y nueve de almacenamiento controlado, se observó el inicio de la pérdida de peso la cual se mantuvo de forma ascendente hasta el término del periodo de aclimatación en todos los tratamientos (figura 2b). El análisis estadístico mostró diferencias significativas $(p<0.05)$ para este estado de madurez.

La pérdida de peso al término del almacenamiento de los jitomates color rojo claro, fue superior cuando los frutos estuvieron a $25^{\circ} \mathrm{C}$ que a $10^{\circ} \mathrm{C}$, incrementándose proporcionalmente con el aumento de la concentración del AEO. De manera que la combinación; estado de madurez, cubierta y temperatura de almacenamiento tuvo un efecto directo sobre el proceso de transpiración. Al respecto, Bautista-Baños et al. (2018) también reportaron que la temperatura de almacenamiento de $25^{\circ} \mathrm{C}$ tuvo un efecto significativo sobre la pérdida de peso en jitomates var. Cuauhtémoc, que el recubrimiento a base de quitosano-ácido acético-AE de limón y la temperatura de $10^{\circ} \mathrm{C}$.

\section{Color}

Los resultados promedio del color de los jitomates rayado mostraron valores de ángulo de matiz entre 50 y 70 al inicio de las evaluaciones, disminuyendo hasta 40 o 50 al término del almacenamiento (figura 3a) $(p<0.05)$. En cuanto a los frutos de jitomate en estado de madurez más avanzado, los cambios de color fueron mínimos ya que iniciaron en un rango 


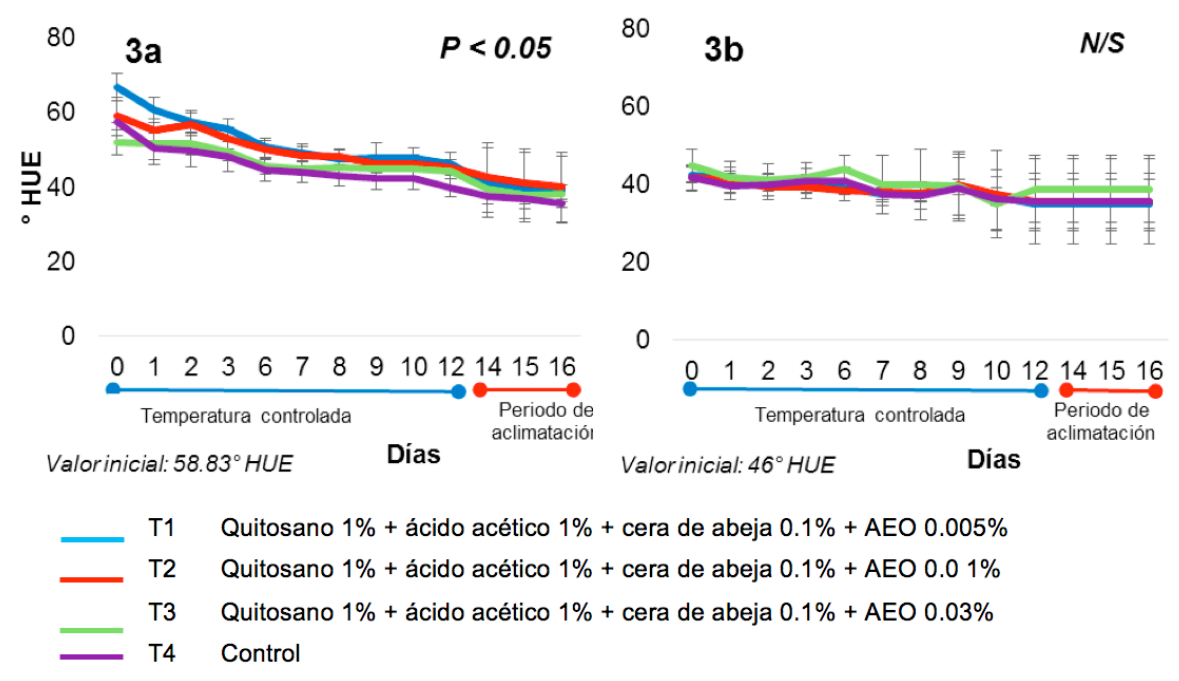

Figura 3. Desarrollo del color en frutos de jitomate color rayado (3a) y rojo claro (3b), tratados con cubiertas de quitosano adicionadas con cera de abeja y $\mathrm{AEO}$ y almacenados a $10^{\circ} \mathrm{C}$ y durante un periodo de aclimatación $\left(25 \pm 2^{\circ} \mathrm{C}\right)$.

de 35 a 45 y concluyeron en valores muy similares; ángulo de matiz $=35-40$.

De manera que en los jitomates evaluados (ambos estados de madurez) los valores de color estuvieron dentro de los reportados por San Martín-Hernández et al. (2012) (ángulo de matiz = entre 35 y 41) para algunas variedades de jitomate tipo Saladette y listos para el consumo. Igualmente, en esta investigación, los valores al término de almacenamiento se mantuvieron dentro de la escala de maduración que siguiere el Departamento de Agricultura de los Estados Unidos (USDA 1997), ya que el color final cayó en la escala número 6 (> de $90 \%$ de la superficie del fruto con coloración roja).

Adicionalmente, en este estudio, el desarrollo de color en los frutos rayados se incrementó durante el proceso de maduración y su interacción con la temperatura de almacenamiento, esto indicó que la cubierta aplicada no modificó la atmósfera interna de los jitomates tratados.

\section{Firmeza, SST ( ${ }^{\circ}$ Brix), $\mathrm{pH}$ y acidez titulable (\%)}

En los colores rayado y rojo claro, los cambios en firmeza fueron notables cuando el producto se trasladó de la temperatura controlada $\left(10^{\circ} \mathrm{C}\right)$ a la de aclimatación $(p<0.05)$ (cuadro 1$)$. Los valores promedio finales para cada estado de madurez fueron aproximadamente de $10 \mathrm{~N}-36 \mathrm{~N}$ (rayado) y $10 \mathrm{~N}-18$ $\mathrm{N}$ (rojo claro), correspondiendo los valores mínimos principalmente a los jitomates rayados $\mathrm{y}$ sin recubrimiento.

De acuerdo con Batu (2004) la firmeza de los frutos de esta investigación está dentro de los niveles mínimos de aceptabilidad $\left(>2.0 \mathrm{~N} \mathrm{~mm}^{-1}\right)$ para que el fruto pueda ser comercializado en el mercado nacional.

Respecto a las variables del contenido de sólidos solubles totales y $\mathrm{pH}$ hubo cambios ligeros en ambas etapas de madurez, cuyos valores fueron similares durante el periodo de almacenamiento $(<5.0 \%$ y 4.5-5.0\%, respectivamente), mientras que para el ácido cítrico $(0.3 \%$ a $0.4 \%)$ los valores fueron en general bajos en comparación a los reportados en otros estudios, debido tal vez al genotipo (Dávila-Aviña et al. 2011, Juárez-López et al. 2009).

Rueda (2013) describió que el sabor de los frutos está vinculado al $\mathrm{pH}$ de los mismos, considerando que un buen sabor del fruto debe tener valores de $\mathrm{pH}$ entre 4.5 y 4.8 en jitomates con madurez comercial. Por otra parte, Cantwell et al. (2007) reportaron que los jitomates listos para consumo humano pueden tener valores de $\mathrm{pH}$ entre 4.2 y 4.8 , donde el último valor es el recomendado para la industria de los jugos de jitomate y conservas.

En este contexto, la vida de anaquel del fruto se favoreció con el uso del recubrimiento formulado con $0.03 \%$ de AEO, ya que el jitomate maduró de manera normal (SST y AT) tal como ocurre con el grupo control; pero la firmeza se mantuvo en $4 \mathrm{~N}$. Los resultados de esta investigación coinciden con otros 
Cuadro 1. Resultado de las variables de calidad (firmeza, SST, pH y acidez titulable) en jitomates cosechados en el estado de madurez rayado y rojo claro, tratados con cubiertas de quitosano adicionadas con cera de abeja y AEO y almacenados a $10^{\circ} \mathrm{C}$ y $25 \pm 2^{\circ} \mathrm{C}$.

RAYADO

\begin{tabular}{|c|c|c|c|c|c|}
\hline $\mathrm{T}\left({ }^{\circ} \mathrm{C}\right)$ & Tratamiento & Firmeza (N) & SST ( ${ }^{\circ}$ Brix) & $\mathrm{pH}$ & AT (\%) \\
\hline \multirow[t]{4}{*}{10} & $\mathrm{~T} 1$ & $36.2 \pm 8.4 a$ & $4.2 \pm 0.3 \mathrm{a}$ & $4.6 \pm 0.2 \mathrm{c}$ & $0.3 \pm 0.3 b$ \\
\hline & $\mathrm{T} 2$ & $36.2 \pm 8.6 \mathrm{a}$ & $4.1 \pm 0.2 \mathrm{a}$ & $4.4 \pm 0.08 \mathrm{ab}$ & $0.3 \pm 0.3 b$ \\
\hline & $\mathrm{T} 3$ & $35.6 \pm 7.2 \mathrm{c}$ & $3.8 \pm 0.4 \mathrm{~b}$ & $4.5 \pm 0.1 \mathrm{a}$ & $0.3 \pm 0.3 b$ \\
\hline & $\mathrm{T} 4$ & $35.5 \pm 7.1 \mathrm{c}$ & $3.5 \pm 0.5 \mathrm{~b}$ & $4.5 \pm 0.1 \mathrm{a}$ & $0.3 \pm 0.3 b$ \\
\hline \multirow[t]{4}{*}{25} & $\mathrm{~T} 1$ & $18.8 \pm 7.3 \mathrm{~b}$ & $4.2 \pm 0.1 \mathrm{a}$ & $4.3 \pm 0.04 a$ & $0.2 \pm 0.04 \mathrm{a}$ \\
\hline & $\mathrm{T} 2$ & $17.3 \pm 6.5 b$ & $4.2 \pm 0.5 \mathrm{a}$ & $4.3 \pm 0.04 a$ & $0.2 \pm 0.05 a$ \\
\hline & $\mathrm{T} 3$ & $14.3 \pm 8.6 \mathrm{c}$ & $4.0 \pm 0.1 \mathrm{a}$ & $4.3 \pm 0.1 \mathrm{a}$ & $0.2 \pm 0.03 a$ \\
\hline & $\mathrm{T} 4$ & $10.6 \pm 5.2 \mathrm{~d}$ & $4.0 \pm 0.9 \mathrm{a}$ & $4.3 \pm 0.1 \mathrm{a}$ & $0.2 \pm 0.03 a$ \\
\hline \multicolumn{2}{|c|}{$\% \mathrm{CV}$} & 0.24 & 0.03 & 0.16 & 0.25 \\
\hline \multirow{2}{*}{\multicolumn{2}{|c|}{$\begin{array}{c}\text { DMSH } \\
\text { Interacción } \mathrm{T}\left({ }^{\circ} \mathrm{C}\right) \text { vs } \\
\text { tratamiento }\end{array}$}} & 0.05 & 0.001 & 0.002 & 0.005 \\
\hline & & 0.05 & 0.05 & NS & NS \\
\hline \multirow{2}{*}{\multicolumn{2}{|c|}{ Valores a la cosecha }} & $55.0 \pm 5.2$ & $3.9 \pm 0.1$ & $4.5 \pm 0.1$ & $0.3 \pm 0.03$ \\
\hline & & & ROJO CLARO & & \\
\hline \multirow[t]{4}{*}{10} & $\mathrm{~T} 1$ & $16.3 \pm 5.9 \mathrm{a}$ & $4.1 \pm 0.7 \mathrm{a}$ & $4.5 \pm 0.06 \mathrm{a}$ & $0.3 \pm 0.02 \mathrm{a}$ \\
\hline & $\mathrm{T} 2$ & $18.0 \pm 3.9 \mathrm{a}$ & $4.0 \pm 0.8 \mathrm{a}$ & $4.5 \pm 0.1 \mathrm{a}$ & $0.3 \pm 0.02 \mathrm{a}$ \\
\hline & $\mathrm{T} 3$ & $18.0 \pm 4.4 \mathrm{a}$ & $3.8 \pm 0.6 \mathrm{a}$ & $4.4 \pm 0.06 a$ & $0.3 \pm 0.04 a$ \\
\hline & $\mathrm{T} 4$ & $16.5 \pm 3.1 \mathrm{a}$ & $4.9 \pm 0.4 \mathrm{a}$ & $4.4 \pm 0.1 \mathrm{a}$ & $0.3 \pm 0.02 \mathrm{a}$ \\
\hline \multirow[t]{5}{*}{25} & $\mathrm{~T} 1$ & $11.4 \pm 4.9 \mathrm{~b}$ & $4.5 \pm 0.9 \mathrm{a}$ & $4.5 \pm 0.1 \mathrm{a}$ & $0.3 \pm 0.04 a$ \\
\hline & $\mathrm{T} 2$ & $10.8 \pm 4.8 \mathrm{bc}$ & $3.5 \pm 0.4 \mathrm{a}$ & $4.4 \pm 0.07 \mathrm{a}$ & $0.3 \pm 0.05 a$ \\
\hline & $\mathrm{T} 3$ & $14.6 \pm 6 \mathrm{~b}$ & $3.2 \pm 0.7 \mathrm{a}$ & $4.4 \pm 0.07 \mathrm{a}$ & $0.3 \pm 0.08 \mathrm{a}$ \\
\hline & $\mathrm{T} 4$ & $10.2 \pm 7.6 \mathrm{bc}$ & $3.5 \pm 0.5 \mathrm{a}$ & $4.5 \pm 0.1 \mathrm{a}$ & $0.3 \pm 0.06 a$ \\
\hline & & 0.37 & 0.17 & 0.01 & 0.25 \\
\hline \multirow{2}{*}{\multicolumn{2}{|c|}{$\begin{array}{c}\text { DMSH } \\
\text { Interacción } \mathrm{T}\left({ }^{\circ} \mathrm{C}\right) \text { vs } \\
\text { tratamiento }\end{array}$}} & 0.05 & 0.001 & 0.002 & 0.005 \\
\hline & & 0.05 & NS & NS & NS \\
\hline \multicolumn{2}{|c|}{ Valores a la cosecha } & $18.7 \pm 4.1$ & $3.6 \pm 1.1$ & $4.7 \pm 0.1$ & $0.36 \pm 0.03$ \\
\hline
\end{tabular}

Los datos se presentan como la media de tres observaciones y su respectiva desviación estándar.

*Letras diferentes indican que las muestras son significativamente diferentes. Comparación de medias con la prueba de Tukey ( $p<0.05)$. T1: quitosano $1 \%$ + ácido acético $1 \%$ + cera de abeja $0.1 \%$ + glicerol $0.3 \%$ + aceite esencial de orégano $0.005 \%$, T2: quitosano $1 \%$ + ácido acético $1 \%+$ cera de abeja $0.1 \%$ + glicerol $0.3 \%$ + aceite esencial de orégano $0.01 \%$, T3: quitosano $1 \%$ + ácido acético $1 \%$ + cera de abeja $0.1 \%$ + glicerol $0.3 \%$ + aceite esencial de orégano $0.03 \%$, T4: control.

estudios. Por ejemplo, Barreto et al. (2016) reportaron que, al término de almacenamiento controlado $\mathrm{y}$ ambiente, jitomates Cherry tratados igualmente con formulaciones a base de quitosano $\left(4 \mathrm{mg} \mathrm{mL}^{-1}\right)$ y aceite esencial de orégano $\left(1.25 \mu \mathrm{g} \mathrm{mL} \mathrm{m}^{-1}\right)$ tuvieron mayor firmeza y menor pérdida de peso en comparación con los no tratados; mientras que, los valores de ácido cítrico y el contenido de sólidos solubles totales fueron similares al control.

\section{Carotenoides}

Se han reportado las propiedades funcionales de los carotenoides en frutas y hortalizas, los cuales actúan como antioxidantes y como supresores de radicales libres (Notario-Medellín y Sosa-Morales 2012). En esta investigación, se determinó el efecto positivo de la aplicación de la temperatura de refrigeración y las cubiertas en los tratamientos quitosano 1\% + 


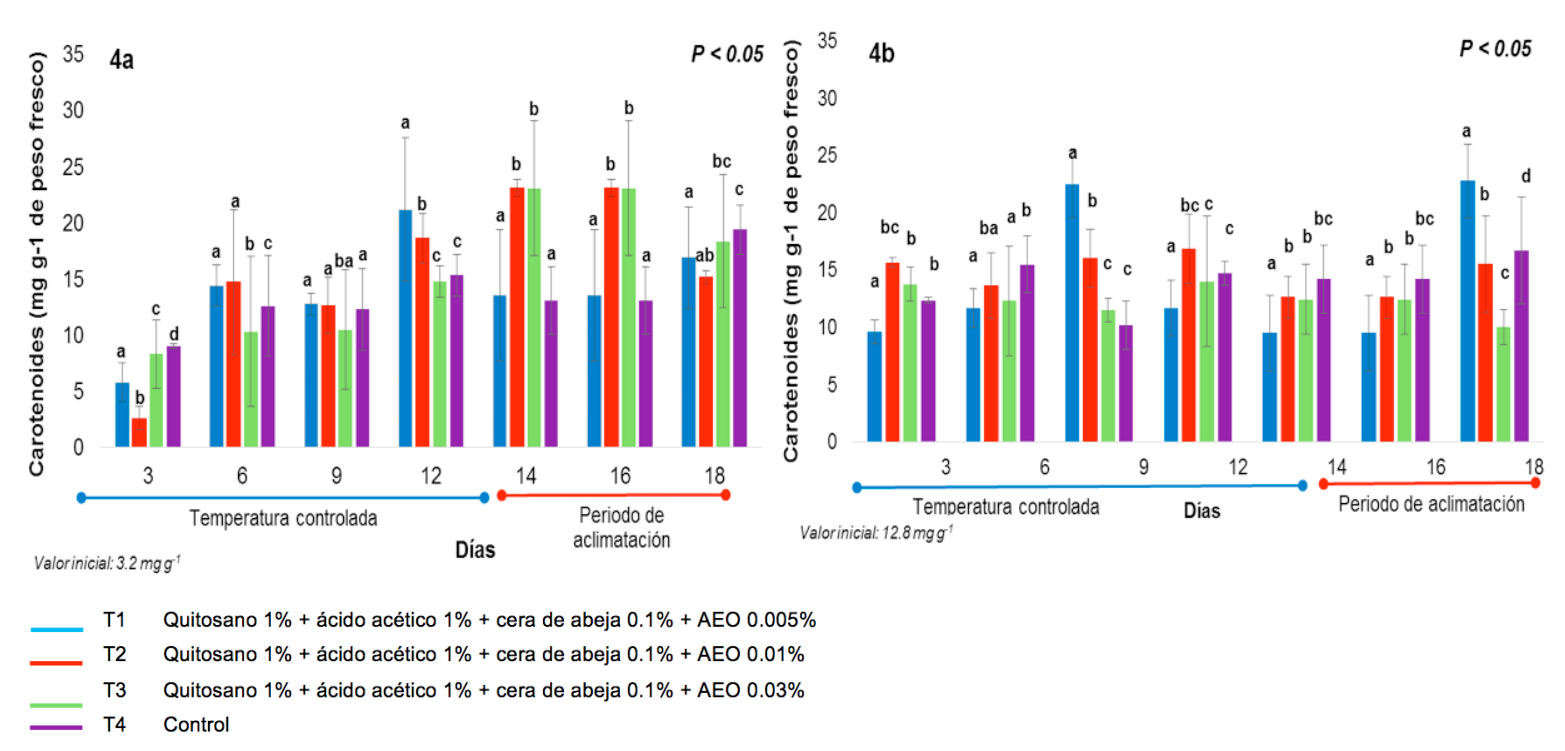

Figura 4. Desarrollo del color en frutos de jitomate color rayado (3a) y rojo claro (3b), tratados con cubiertas de quitosano adicionadas con cera de abeja y $\mathrm{AEO}$ y almacenados a $10^{\circ} \mathrm{C}$ y durante un periodo de aclimatación $\left(25 \pm 2^{\circ} \mathrm{C}\right)$.

ácido acético $1 \%$ + cera de abeja $0.1 \%$ + AEO 0.01\%) y quitosano $1 \%+$ ácido acético $1 \%$ + cera de abeja $0.1 \%$ + AEO $0.03 \%$, principalmente en los jitomates color rayado con valores promedio finales de $23 \mathrm{mg}$ $\mathrm{g}^{-1}$ de peso fresco $(p<0.05)$ a los 14 y 16 días de almacenamiento (figura 4a). Los frutos de color rojo claro, en el tratamiento (quitosano 1\% + ácido acético 1\% + cera de abeja $0.1 \%$ + AEO $0.005 \%$ ) después de 18 días de almacenamiento, los jitomates presentaron valores mayores, $23 \mathrm{mg} \mathrm{g}^{-1}$ de peso fresco (figura $4 \mathrm{~b}$ ).

La literatura reporta diferentes valores promedio de acuerdo con la variedad o cultivar. Así, en diferentes variedades de jitomate Cherry se obtuvieron valores promedio de $9.9 \mu \mathrm{L} \mathrm{g}^{-1}$ (Muratore et al. 2005) y de 4.9 a $7.1 \mu \mathrm{L} \mathrm{g}^{-1}$ (Zanfini et al. 2007). Estos últimos autores, reportaron en la variedad Bola valores de 23 a $35 \mu \mathrm{Lg}^{-1}$.

\section{Bacterias, hongos y levaduras}

No hubo desarrollo de microorganismos en los jitomates color rayado, incluyendo el control. Sin embargo, en los frutos rojo claro, se aislaron microorganismos en todos los tratamientos (cuadro 2). En los frutos sin recubrimiento el valor de UFC fue significativamente mayor $(p<0.05)$ que en los cubiertos. En general, el número menor de UFC correspondió a los tratamientos quitosano $1 \%$ + ácido acético $1 \%$ + cera de abeja $0.1 \%$ + AEO $0.005 \%$ y quitosano $1 \%+$ ácido acético $1 \%$ + cera de abeja $0.1 \%$ + AEO $0.03 \%$. Al respecto, Ramos-García et al. (2012) reportaron 100\% de inhibición de la bacteria E. coli DH5 $\alpha$ en jitomates provenientes en los mismos estados de madurez que en el presente estudio, mediante la aplicación de formulaciones con quitosano $1 \%$, cera de abeja $0.1 \%$ y aceite esencial de limón $0.01 \%$.

\section{Hongos fitopatógenos}

Los frutos color rojo claro, la reducción de hongos postcosecha fue significativa $(p<0.001$ ) (mayor a $50 \%$ ) con la aplicación de los recubrimientos, principalmente con la concentración mayor del AEO $(0.03 \%)$ (cuadro 3$)$. Estos resultados coinciden con otros experimentos en los que la aplicación de formulaciones con quitosano o aceites esenciales como el orégano y té limón fueron efectivos en contra de microorganismos patógenos del jitomate (Athayde et al. 2016; Barreto et al. 2016). En estos estudios, el control de hongos como Rhizopus stolonifer y Alternaria sp. fue mayor en comparación con los no tratados.

\section{Evaluación sensorial}

De la prueba sensorial de los jitomates color rayado, el tratamiento quitosano $1 \%$ + ácido acético 1\% + cera de abeja $0.1 \%$ + AEO $0.005 \%$ obtuvo el puntaje mayor en la categoría de color y aroma mientras que el quitosano $1 \%$ + ácido acético $1 \%$ + cera de abeja $0.1 \%$ + AEO $0.03 \%$ correspondió al sabor. Los jitomates control en estado rojo claro tuvieron la mejor aceptación en las tres variables (cuadro 4). Sobre el tema, Barreto et al. (2016) reportaron que la combinación de quitosano 
Cuadro 2. Presencia de microorganismos en jitomates cosechados en el estado de madurez rojo claro, tratados con cubiertas de quitosano adicionadas con cera de abeja y AEO al término del almacenamiento.

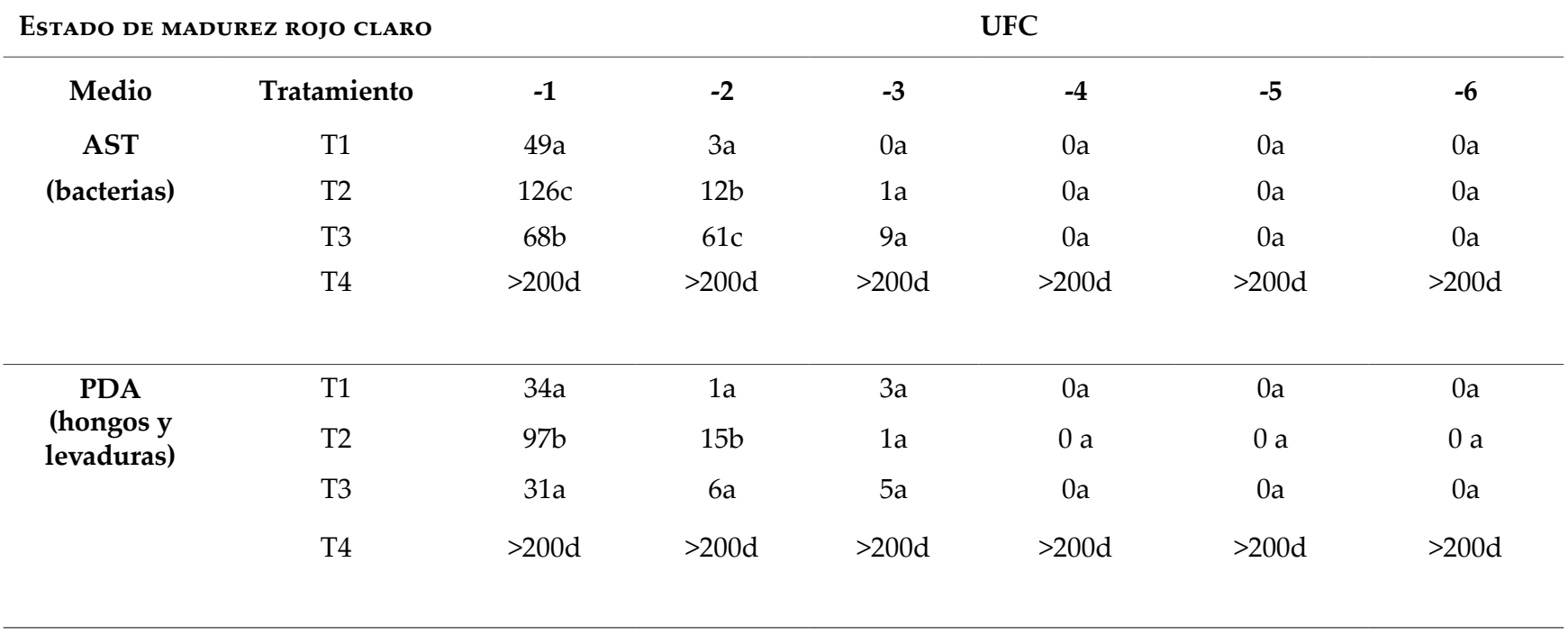

*AST: agar soya tripticaseína, PDA: papa dextrosa Agar, UFC: unidades formadoras de colonias.

* Letras diferentes indican que las muestras son significativamente diferentes. Comparación de medias con la prueba de Tukey ( $p<0.05)$.

T1: Q $1 \%$ + ácido acético $1 \%$ + cera de abeja $0.1 \%$ + glicerol $0.3 \%$ + aceite esencial de orégano $0.005 \%$, T2: Q1\% + ácido acético $1 \%$ + cera de abeja $0.1 \%$ + glicerol $0.3 \%$ + aceite esencial de orégano $0.01 \%$, T3: Q1\% + ácido acético $1 \%$ + cera de abeja $0.1 \%$ + glicerol $0.3 \%$ + aceite esencial de orégano $0.03 \%$ y T4: control.

Cuadro 3. Género, frecuencia, incidencia y severidad de los fitopatógenos aislados de jitomates cosechados en el estado de madurez rojo claro, tratados con cubiertas de quitosano, cera de abeja y AEO al término del almacenamiento.

\begin{tabular}{|c|c|c|c|c|}
\hline Tratamiento & GÉneros & $\begin{array}{c}\text { FRECUENCIA DE } \\
\text { GÉNEROS AISLADOS }\end{array}$ & INCIDENCIA $(\%)^{*}$ & ÍNDICE DE SEVERIDAD \\
\hline \multirow[t]{3}{*}{$\mathrm{T} 1$} & Alternaria sp. & $44.4 \%$ & & \\
\hline & Fusarium sp. & $22.2 \%$ & $27 \mathrm{~b}$ & 1.6 \\
\hline & Geotrichum sp. & $33.3 \%$ & & \\
\hline $\mathrm{T} 2$ & Alternaria sp. & $100 \%$ & $18 \mathrm{a}$ & 1.3 \\
\hline \multirow[t]{3}{*}{$\mathrm{T} 3$} & Cladosporium sp. & $42.8 \%$ & & \\
\hline & Fusarium sp. & $28.5 \%$ & $16 \mathrm{a}$ & 1.5 \\
\hline & Botrytis sp. & $28.5 \%$ & & \\
\hline \multirow[t]{4}{*}{$\mathrm{T} 4$} & Alternaria sp. & $31.8 \%$ & & \\
\hline & Fusarium sp. & $13.6 \%$ & $49 c$ & 3.6 \\
\hline & Cladosporium sp. & $27.2 \%$ & & \\
\hline & Botrytis sp. & $22.7 \%$ & & \\
\hline
\end{tabular}

Índice de severidad: $1=0 \%, 2=1-25 \%, 3=26-50 \%, 4=51-75 \%$ y $5=76-100 \%$ de daño superficial.

* Letras diferentes indican que las muestras son significativamente diferentes. Comparación de medias con la prueba de Tukey ( $p<0.05)$. T1: quitosano 1\% + ácido acético $1 \%$ + cera de abeja $0.1 \%$ + glicerol $0.3 \%$ + aceite esencial de orégano $0.005 \%$, T2: quitosano $1 \%$ + ácido acético $1 \%$ + cera de abeja $0.1 \%$ + glicerol $0.3 \%$ + aceite esencial de orégano $0.01 \%$, T3: quitosano $1 \%$ + ácido acético $1 \%$ + cera de abeja $0.1 \%$ + glicerol $0.3 \%$ + aceite esencial de orégano $0.03 \%$ y T4: control. 
Cuadro 4. Análisis sensorial de jitomates cosechados en el estado de madurez rayado y rojo claro, tratados con cubiertas de quitosano adicionadas con cera de abeja y AEO al término del almacenamiento.

\begin{tabular}{|c|c|c|c|}
\hline Tratamiento & COLOR & Авома & SABOR \\
\hline \multicolumn{4}{|c|}{ Rayado } \\
\hline $\mathrm{T} 1$ & $7.8 \pm 0.4 b$ & $6.4 \pm 0.4 \mathrm{a}$ & $7.2 \pm 0.6 \mathrm{~b}$ \\
\hline $\mathrm{T} 2$ & $6.0 \pm 0.4 \mathrm{ab}$ & $6.0 \pm 0.4 \mathrm{a}$ & $4.8 \pm 0.6 \mathrm{ab}$ \\
\hline $\mathrm{T} 3$ & $6.8 \pm 0.4 \mathrm{ab}$ & $6.4 \pm 0.4 \mathrm{a}$ & $7.4 \pm 0.6 b$ \\
\hline $\mathrm{T} 4$ & $7.0 \pm 0.4 b$ & $5.4 \pm 0.4 a$ & $6.6 \pm 0.6 b$ \\
\hline$\% \mathrm{CV}$ & 22.5 & 19.8 & 30.3 \\
\hline DMSH & 1.64 & 1.64 & 2.37 \\
\hline $\begin{array}{l}\text { Interacción } \\
\mathrm{T}\left({ }^{\circ} \mathrm{C}\right) \text { vs } \\
\text { tratamiento }\end{array}$ & NS & NS & NS \\
\hline \multicolumn{4}{|c|}{ Rojo claro } \\
\hline $\mathrm{T} 1$ & $5.7 \pm 0.3 a$ & $7.0 \pm 0.4 \mathrm{a}$ & $6.8 \pm 0.6 \mathrm{a}$ \\
\hline $\mathrm{T} 2$ & $5.8 \pm 0.3 a$ & $6.6 \pm 0.4 \mathrm{a}$ & $5.4 \pm 0.6 \mathrm{a}$ \\
\hline $\mathrm{T} 3$ & $5.8 \pm 0.3 a$ & $7.0 \pm 0.4 \mathrm{a}$ & $6.8 \pm 0.6 \mathrm{a}$ \\
\hline $\mathrm{T} 4$ & $7.3 \pm 0.4 b$ & $8.0 \pm 0.5 \mathrm{a}$ & $7.5 \pm 0.7 \mathrm{a}$ \\
\hline$\% \mathrm{CV}$ & 19.3 & 21.5 & 31.6 \\
\hline DMSH & 1.45 & 1.8 & 2.56 \\
\hline $\begin{array}{l}\text { Interacción } \\
\mathrm{T}\left({ }^{\circ} \mathrm{C}\right) \text { vs } \\
\text { tratamiento }\end{array}$ & NS & NS & NS \\
\hline
\end{tabular}

Los datos se presentan como la media de tres observaciones y su respectiva desviación estándar.

* Letras diferentes indican que las muestras son significativamente diferentes. Comparación de medias con la prueba de Tukey $(p<0.05)$. T1: quitosano $1 \%$ + ácido acético $1 \%$ + cera de abeja $0.1 \%$ + glicerol $0.3 \%$ + aceite esencial de orégano $0.005 \%$, T2: quitosano $1 \%$ + ácido acético $1 \%$ + cera de abeja $0.1 \%$ + glicerol $0.3 \%$ + aceite esencial de orégano $0.01 \%$, T3: quitosano $1 \%$ + ácido acético $1 \%$ + cera de abeja $0.1 \%$ + glicerol $0.3 \%$ + aceite esencial de orégano $0.03 \%$ y T4: control.

con AEO, mejoró la apariencia, sabor y color de jitomates Cherry en estado maduro y la consiguiente aceptación del producto por parte de los evaluadores.

Los productores mexicanos involucrados principalmente en el sector de hortalizas incluyendo el jitomate han adoptado en general, variedades y cultivares nuevos, así como tecnologías nuevas con la finalidad de incrementar su producción. La adición de tecnologías amigables con el medio ambiente para prolongar la vida de anaquel de este cultivo de importancia comercial para México, como las que se han evaluado en esta investigación, mantendrá o mejorará la calidad del producto y por consiguiente proveerá de beneficios económicos a los interesados (Romanazzi et al. 2017).
Las formulaciones que incluyen quitosano en combinación con cera de abeja y aceites esenciales obtenidos de orégano pueden ser una alternativa no química disponible para controlar microorganismos patógenos y extender la vida de anaquel del jitomate. Sin embargo, antes de recomendaciones mayores será necesario realizar evaluaciones a nivel comercial y directamente en empacadoras. Por otro lado, se sabe que el jitomate se consume fresco o se utiliza en la manufactura de productos procesados tales como puré, pasta, polvo, catsup, salsa, sopas y tomates enlatados, entre otros, entonces, la evaluación de las formulaciones deberá considerar el destino final de este producto agrícola.

\section{Conclusiones}

El recubrimiento con la concentración de AEO de $0.03 \%$ mantuvo la calidad poscosecha de los jitomates, al reducir la tasa respiratoria y pérdida de peso; además mantuvo la firmeza mayor y contenido de carotenoides. La aplicación de los recubrimientos inhibió y controló los microrganismos, principalmente en los jitomates rojo claro. Las temperaturas de almacenamiento también fueron un factor determinante en la vida poscosecha de esta hortaliza.

\section{Agradecimientos}

A la Cátedra CONACYT número 772 otorgado a RIVA. 


\section{LITERATURA CITADA}

Athayde AJAA, De Oliveira PDL, Guerra ICD, Da Conceição ML, De Lima MAB, Arcanjo NMO, Madruga MS, Berger LR R, De Souza EL. 2016. A coating composed of chitosan and Cymbopogon citratus (Dc. Ex Nees) essential oil to control Rhizopus soft rot and quality in tomato fruit stored at room temperature. Journal of Horticultural Science and Biotechnology 91(6): 1-10. http://doi.org /10.1080/14620316.2016.1193428

Barnett HL, Hunter BB. 2003. Illustrated Genera of imperfect fungi. St. Paul, USA: APS Press.

Barreto TA, Andrade SCA, Maciel JF, Arcanjo NMO, Madruga MS, Meireles B, Cordeiro AMT, Souza EL, Magnani M. 2016. A chitosan coating containing essential oil from Origanum vulgare L. to control postharvest mold infections and keep the quality of cherry tomato fruit. Frontiers in Microbiology 7: 1724. http://doi. org/10.3389/fmicb.2016.01724

Batu, A. 2004. Determination of acceptable firmness and colour values of tomatoes. Journal of Food and Engineering 61(3): 471-475. http://doi.org/10.1016/S02608774(03)00141-9

Bautista-Baños S., Ventura-Aguilar RI, Correa-Pacheco Z, Corona-Rangel M L. 2017. Chitosan: a versatile antimicrobial polysaccharide for fruit and vegetables in postharvest-- a review. Revista Chapingo serie Horticultura 23(2): 103-121. http://dx.doi.org/10.5154/r. rchsh.2016.11.030.

Bautista-Baños S, González-Soto R, Ramos-García ML. 2018. Propiedades físicas de películas de quitosano adicionadas con aceite esencial de limón y su impacto en la vida de anaquel del jitomate (Lycopersicon esculentum L). Revista Mexicana de Ingeniería Química 17(1): 1-11.

Cantwell M, Stoddard S, Lestrange M, Aegerter B. [internet]. 2007. Statewide fresh market tomato variety trials: Field and postharvest evaluations for 2006. University of California Cooperative Extension. Disponible en: http://vric.ucdavis.edu/pdf/TOMATO/FMTomatoTrials2006.pdf

Dávila-Aviña JEJ, Villa-Rodíguez J, Cruz-Valenzuela R, Rodríguez-Armenta M, Espino-Días M, Ayala-Zavala JF, Olivas-Orozco GI, Basilio H, González-Aguilar G. 2011. Effect of edible coatings, storage time and maturity stage on overall quality of tomato fruits. American Journal of Agricultural and Biological Sciences 6 (1): 162-171. http://dx.doi.org/10.3844/ajabssp.2011.162.171

Fagundes C, Palou L, Monteiro AR, Pérez-Gago MB. 2014. Effect of antifungal hydroxypropyl methylcellulose-beeswax edible coatings on gray mold development and quality attributes of cold-stored cherry tomato fruit. Postharvest Biology and Technology 92: 1-8. http://doi. org/10.1016/j.postharvbio.2014.01.006

[FAOSTAT] Food and Agriculture Organization of the United Nations Statistics Division. [internet]. 2015. Crops. Disponible en: http://www.fao.org/faostat/en/\#data/QC

García-Camarillo EA, Quezada-Viay MY, Moreno-Lara J, Sánchez-Hernández G, Moreno-Martínez E, Pérez-Re- yes MCJ. 2006. Actividad antifúngica de aceites esenciales de canela (Cinnamomum zeylanicum Blume) y orégano (Origanum vulgare L.) y su efecto sobre la producción de aflatoxinas en nuez ecanera [Carya illinoensis (F.A. Wangenh) K. Koch] Revista Mexicana de Fitopatología 24(1): 8-12.

Juárez-López $\mathrm{P}$, Castro-Brindis R, Colinas-León T, Ramírez-Vallejo P, Sandoval-Villas M, Reed DW, Cisneros-Zevallos L, King S. 2009. Evaluación de calidad en frutos de siete genotipos nativos de jitomate (Lycopersicum sculentum var. cerasiforme). Revista Chapingo serie Horticultura 15(2): 5-9.

Muratore G, Licciardello F, Maccarone E. 2005. Evaluation of the chemical quality of new type of small-size tomato cultivar, the plum tomato (Lycopersicum esculentum). Italian Journal of Food Science 1(17): 75-81.

Notario-Medellín CM, Sosa-Morales ME. 2012. El jitomate (Solanum lycopersicum L.): aporte nutrimental, enfermedades post cosecha y tecnologías para su almacenamiento en fresco. Temas selectos de la Ingeniería en Alimentos 6(1): 40-53.

Pontigo-Suárez AG, Trejo-Márquez MA, Lira-Vargas AA. 2015. Desarrollo de un recubrimiento con efecto antifúngico y antibacterial a base de aceite esencial de orégano para conservación de papaya "Maradol". Revista Iberoamericana de Tecnología Postcosecha 16(1): 58-63.

Ramos ML. 2012. Recubrimientos biodegradables para el control de microorganismos patógenos y conservación de la calidad de frutos de jitomate (Lycopersucum esculentum L.). Tesis de Doctorado en Ciencias. México: Instituto Politécnico Nacional.

Ramos-García ML, Bautista-Baños S., Barrera-Necha LL, Bosquez-Molina E, Alia-Tejacal I, Estrada-Carrillo M. 2010. Compuestos antimicrobianos adicionados en recubrimientos comestibles para uso en productos hortofrutícolas. Revista Mexicana de Fitopatología 28: 44-57.

Ramos-García M, Bosquez-Molina E, Hernández-Romano J, Zavala-Padilla G, Terrés-Rojas E, Alia-Tejacal I, Barrera-Necha L, Hernández-López M, Bautista-Baños S. 2012. Use of chitosan-based edible coatings in combination with other natural compounds, to control Rhizopus stolonifer and Escherichia coli $\mathrm{DH} 5 \alpha$ in fresh tomatoes. Crop Protection 38(1): 1-6. http://doi.org/10.1016/j.cropro.2012.02.016

Rodríguez-Amaya DB. 1999. Carotenoides y preparación de alimentos: La retención de los carotenoides, provitamina A en alimentos preparados, procesados y almacenados. Campinas, Brasil: Universidad Estatal de Campinas.

Rodríguez-Pedroso AT, Ramírez-Arrebato MA, Rivero-González D, Bosquez-Molina E, Barrera-Necha LL, Bautista-Baños S. 2009. Propiedades químico-estructurales y actividad biológica de la quitosano en microorganismos fitopatógenos. Revista Chapingo Serie Horticultura 15(3): 307-319. 
RomanazzI G, Feliziani E, Bautista-Baños S, Sivakumar D. 2017. Shelf life extension of fresh fruit and vegetables by chitosan. Critical Reviews in Food Science and Nutrition 57(3): 579-601 http://doi.org/10.1080/10408398.20 14.900474

Rueda IJ. 2013. Estudio de la influencia de factores pre- y poscosecha en la calidad y vida útil del tomate tipo raf. Tesis de licenciatura. Almería, España: Escuela Politécnica Superior.

San Martín-Hernández C, Ordaz-Chaparro VM, Sánchez-García P, Colinas-León MTB, Borges-Gómez L. 2012. Calidad de tomate (Solanum lycopersicum L.) producido en hidroponia con diferentes granulometrías de tezontle. Agrociencia 47(3): 243-254.

Sivakumar D, Bautista-Baños S. 2014. A review on the use of essential oils for postharvest decay control and maintenance of fruit quality during storage. Crop Protection 64: 27-37. http://doi.org/10.1016/j.cropro.2014.05.012

Tulloch AP. 1969. The composition of beeswax and other waxes secreted by insects. Lipids 5: 247-258. http://doi. org/10.1007/BF02532476

[USDA] United States Department of Agriculture. [internet].1997. United States Standards for Grade of Fresh Tomatoes. Disponible en: https://www.ams.usda.gov/ sites/default/files/media/Tomato_Standard\%5B1\%5D. pdf

Villegas C, Albarracin W. 2016. Aplicación y efecto de un recubrimiento comestible sobre la vida útil de la mora de castilla (Rubus glaucus Benth). Vitae 22(3): 202-209. http://doi.org/10.17533/uedea.vitae.v23n3a06

Zanfini A, Dreasi E, La Rosa C, Addario C, Corti P. 2007. Quantitative variations of the main carotenoids in Italian tomatoes in relation to geographic location harvest time varieties and ripening stage. Italian Journal of Food Science 19(2): 181-190. 